\title{
Improvement of Detection Methods and Further Characterization of Spiroplasma citri, the Causal Agent of Citrus Stubborn Disease in Egypt
}

\author{
Mohamed Mannaa $^{1^{*}}$, Anna Maria D’Onghia ${ }^{2}$, Khaled Djelouah ${ }^{2}$, Giuseppe Cavallo ${ }^{2}$, Franco Valentini ${ }^{2}$ \\ ${ }^{1}$ CIHEAM-Department of Plant Pathology, Faculty of Agriculture, Cairo University, Giza, Egypt; ${ }^{2}$ CIHEAM-Mediterranean Agro- \\ nomic Institute of Bari, Bari, Italy. \\ Email: ${ }^{*}$ mannaa_mohamed@yahoo.com
}

Received September $29^{\text {th }}, 2012$; revised November $3^{\text {rd }}, 2012$; accepted November $10^{\text {th }}, 2012$

\begin{abstract}
Stubborn disease of citrus is one of the main causes of quality deterioration of citrus fruits in Egypt. The early detection and the molecular characterization of the causal agent are vital for revealing its real distribution and for management. In 2011, several samples were collected at different times of the year from stubborn suspected symptomatic trees within the main citrus growing area in Egypt, the Nile-delta region. After culturing the causal agent on artificial LD8 media from the field fresh samples, two new and improved methods of biological indexing were set up and compared with the traditional method in order to increase the detection efficiency by increasing the greenhouse transmission rate; which reached $85 \%$ with the new inverse inoculation method. Different PCR primer pairs were evaluated for their detection efficiency of the Egyptian Isolates of Spiroplasma citri and the most specific primer pair for these local isolates was determined. Improving the efficiency of biological indexing, along with determining the most specific and efficient PCR primer pair for the detection, will enhance and facilitate the citrus certification programs in Egypt, making them better tools for the early detection of stubborn disease. Furthermore obtained Egyptian isolates were characterized molecularly by the analysis of the obtained sequences showing close relationship with the Moroccan strain (GII3).
\end{abstract}

Keywords: Biological Indexing; Spiroplasma citri; PCR; Citrus Stubborn Disease; Egypt

\section{Introduction}

Stubborn disease of citrus is one of the most important graft-transmissible diseases affecting citrus trees, particularly in warm climatic regions. It is caused by the prokaryote Spiroplasma citri, which is a plant pathogenic bacterium belonging to the class Mollicutes, a group of microorganisms phylogenetically related to low G-C content Gram-positive bacteria [1]. Spiroplasma citri was first reported in Egypt by Nour El-din in 1967 [2], who described the symptoms of the disease and suggested that the causal agent was graft-transmissible. Later, it was isolated and cultured [3].

Citrus is considered to be the main fruit crop in Egypt. The annual production of orange fruit, as the most important citrus variety, averages 3.7 million tons in 2011 [4], equaling $37.7 \%$ of the total fruit trees production. Citrus is produced mainly in the Nile Delta and valley (old lands), where nearly $71 \%$ of the total citrus area in this region is located [5]. In 2011, although production was forecast up in Egypt, exports were forecast down-

*Corresponding author. ward due to uneven quality [4]. This drew attention to the epidemiology and the precise detection of the quality diseases in the area, such as citrus stubborn disease (CSD), which would help with the management of such disease.

It was noticed on several previous reports that the rate of greenhouse transmission of Spiroplasma citri, determined by the traditional method of biological indexing on the indicator plant, is relatively low and that the time required for the symptoms' appearance on the indicator plant is long. This could be due to the low concentration of the pathogen in the budstick used specially during the cold seasons; therefore, the traditional method of biological indexing needs to be modified in such a way as to overcome the problems of the low rate of successful green-house transmission.

\section{Material and Method}

\subsection{Field Observation and Sampling}

First, Observations in various fields were carried out at different times of the year (October 2010, May, July and 
August 2011), in order to check for symptoms of CSD. During the survey, only symptomatic samples were considered. Further, three symptomatic and off-season fruits were collected per suspected tree. A total of 130 samples were collected at different times of the year: 100 samples belonging to three orchards at $\mathrm{Al}$ Qalyoubia (Washington navel orange and sweet orange), and 30 samples belonging to the experimental orchard at the Faculty of Agriculture, Cairo University (Sweet orange).

The confirmation of the visual symptoms observed was carried out by culturing in LD8 media and microscopic observation of the S. citri.

\subsection{Isolation and Culturing}

Petiole leaf midribs or fruit columella were excised, surface disinfested and diced with a sterile razor blade in 5 $\mathrm{ml}$ of LD8 broth medium [6], passed through a $0.45-\mu \mathrm{m}$ filter, and incubated at $30^{\circ} \mathrm{C}$. The presence of $S$. citri was confirmed after 3 to 14 days by examining $10 \mu \mathrm{l}$ of culture medium by dark-field microscopy at $\times 400$ to 1000 for the presence of motile, helical spiroplasma.

\subsection{Biological Indexing}

Three different methods of biological indexing (traditional method, inoculated indicator and inverse inoculation) were conducted and compared in order to evaluate the most efficient method and the most suitable conditions for transmission of the $S$. citri in the greenhouse. For that, young shoots with small emerging leaves from symptomatic trees were collected to be used in these trials.

Positive control trees, as well as negative control from healthy trees, were also included in the tests. Different aspects were evaluated, including the successful transmission rate and the time required for the appearance of stubborn symptoms on the indicator plant.

\subsubsection{Traditional Method}

As reported by Roistacher in 1991 [7], side grafting and leaf batch grafting were performed; collected budwood (stem pieces that were $5-7 \mathrm{~mm}$ in diameter from Stubborn infected trees) were side-grafted onto the one-yearold Madame Vinous seedlings (stubborn indicator plant). After sealing the graft with parafilm, and then labeling and enclosing it inside a plastic bag, the inoculated plants and the negative controls were maintained in a warm, conditioned greenhouse. After $1-2$ weeks, the plastic bags were opened at the top to reduce humidity and observations of the symptoms were carried out weekly.

\subsubsection{Inoculated Indicator}

Wood cuttings containing $4-6$ nodes of the indicator
"Madame Vinous" were firstly inoculated by chip budding or by leaf inoculation using the bark tissue collected from the sample sources; then, the inoculated indicator cuttings were grafted onto Sour orange rootstock (Figure 1) and enclosed inside a plastic bag in order to keep high humidity inside. The inoculated plants were maintained in a warm conditioned greenhouse. After ten days, the plastic bags were opened at the top in order to reduce the inside humidity, grafting success was evaluated and symptoms observations were carried out weekly.

\subsubsection{Inverse Inoculation}

This new technique was set up in order to overcome the limitations of the traditional indexing related to the low concentration of $S$. citri in the stubborn infected sample and the long time needed for the diffusion of the pathogen in the plants. This method is the reverse of the inoculated indicator method, as it consists of the inoculation of a cutting from the sample to be tested with a bud from Madame Vinous sweet orange indicator, and then the obtained inoculated cutting was grafted onto sour orange rootstock (Figure 2). Symptoms observations were carried out weekly on leaves emerging from the indicator bud.

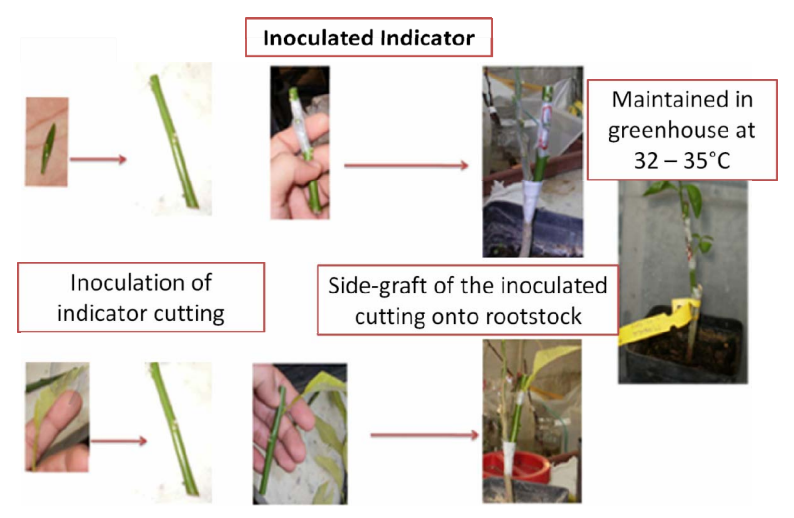

Figure 1. The Inoculated Indicator method.

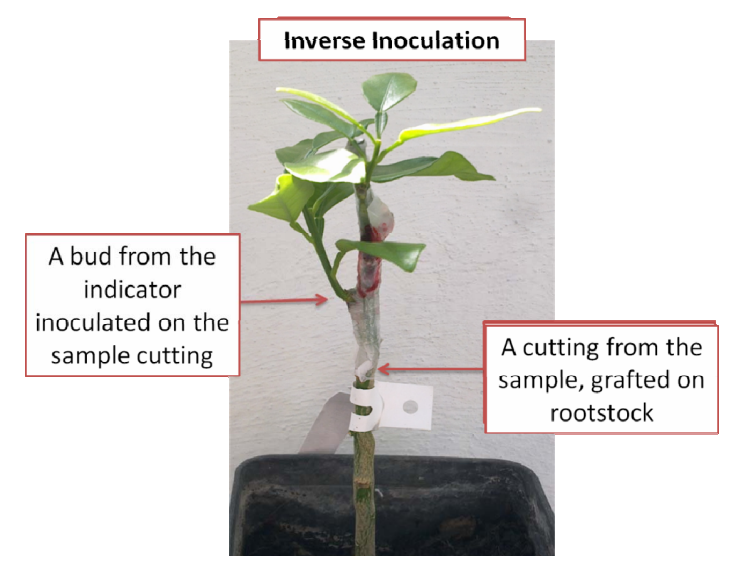

Figure 2. The Inverse Inoculation method. 


\subsection{Molecular Detection by PCR}

Fruit columella and leaf midribs of the collected samples were utilized to perform molecular assays by conventional PCR. Positive as well as negative controls from healthy trees were included. DNA extraction was performed using the cetyl trimethyl ammonium bromide (CTAB)-based total nucleic acid extraction protocol, as reported by Doyle in 1991 [8].

Conventional PCR assays were conducted using three primer pairs; Spiralin [9], P58 and P89 [10] targeting Spiralin gene, Putative adhesion like multigene and Putative adhesion gene. (Table 1), in order to determine the most efficient primer pair for the detection of the Egyptian isolates of S. citri. Reaction conditions for the PCR assay was set as follows: $1.5 \mu \mathrm{l}$ of DNA template in $20 \mu \mathrm{l}$ of reaction mix, which included 1X DreamTaq Buffer, $0.4 \mu \mathrm{l}$ each of $[10 \mathrm{mM}$ dNTPs (Sigma), $10 \mu \mathrm{M}$ forward primer, $10 \mu \mathrm{M}$ reverse primer], and $0.1 \mu \mathrm{l}$ of DreamTaq. Reactions were performed on the Termocycler as follows: 5 min of denaturation at $95^{\circ} \mathrm{C}$; followed by 40 cycles of $95^{\circ} \mathrm{C}$ for $30 \mathrm{sec}, 56^{\circ} \mathrm{C}$ for $30 \mathrm{sec}$, and $72^{\circ} \mathrm{C}$ for $90 \mathrm{sec}$; followed by $5 \mathrm{~min}$ of elongation at $72^{\circ} \mathrm{C}$.

\subsection{Molecular Characterization}

PCR positive samples representing the positive trees were subjected to further molecular characterization by sequence analysis of the putative adhesion protein gene (P89). In such, the amplified sequences (P89) after PCR were inserted into the commercial plasmid vector pGEMT (promega-Italy) by a ligation, and then cloned into $E$. coli DH5a (IAMB) competent cells. Following enrichment, the DNA plasmids were extracted with miniprep and to verify presence of the appropriate PCR amplified (P89) sequence, a digestion reaction was performed before sending it for sequencing.

The plasmids were sent to PRIMM-Milan for sequencing and then using the BLAST the nucleotide sequence provided, were then subjected to analysis and alignment using CLC Genomic workbench 3, investigating the percentage of identify with other $S$. citri strains on Gen bank.

\section{Results and Discussion}

Citrus stubborn disease seems to be widely spread in the Nile Delta region Egypt, as $20 \%$ of the orchards visited showed symptoms associated with CSD. The symptoms were displayed as follows: on the trees (general stunted tree growth and dense foliation on the branches), on leaves (upright foliation, small leaves with short internodes, cup shaped, typical chlorosis and mottling) and on fruits (lopsided acorn shaped, aborted seeds, styler end greening, small-sized fruits, offseason flowering and fruit setting) (Figure 3).

\subsection{Biological Indexing}

The comparison which was carried out between the three methods was concerning the percentage of successful $S$. citri transmission and the time required for the appearance of the first symptoms on the indicator plant.

Regarding the $S$. citri transmission rate which was evaluated through the observation of typical symptoms on the leaves of the indicator plants that include (chloro- sis, cup shaped leaves with short internodes and small sized) (Figure 4), in comparison with the negative con- trol plants which did not show any abnormalities. The obtained results (Table 2), showed low transmission rates by using the traditional and inoculated cutting methods, on the contrary, a high $S$. citri transmission rate was achieved with the new inverse inoculation method. Concerning the appearance of the first symptoms post- inoculation, the inoculated cutting technique allowed a faster development of symptoms compared with traditional method, first symptoms on the indicator cutting appeared. 5 weeks post-inoculation, on the other hand, 3 months were required to observe the symptoms by using traditional biological indexing. Surprisingly, in the new set up method "the inverse inoculation" symptoms could be observed 4 weeks post-inoculation. In fact it needed short time to observe new flushes evidencing the first chlorosis in the small leaves.

Table 1. The sequence of the used primer pair.

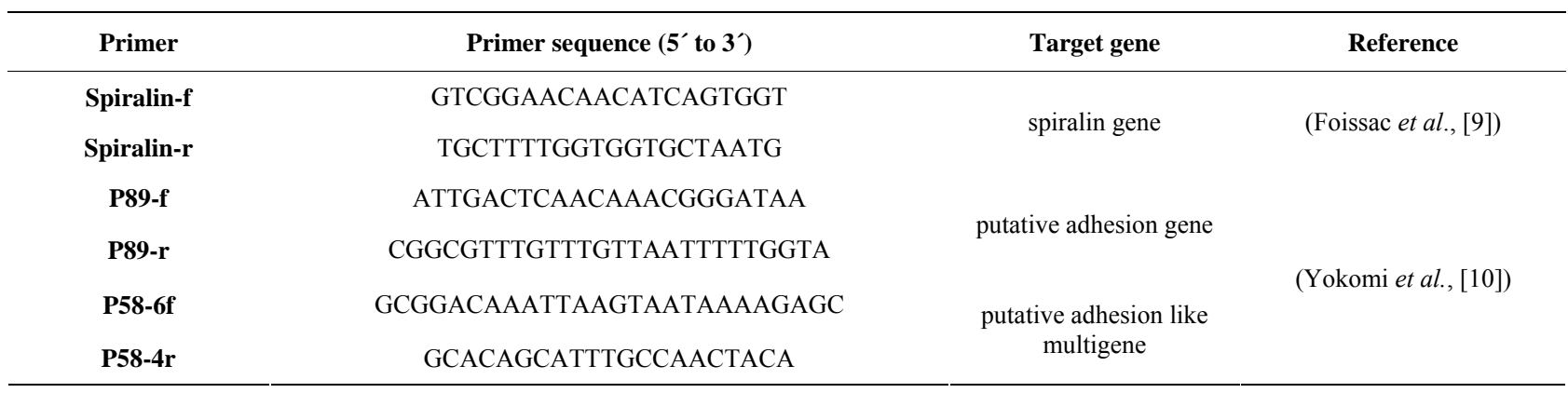



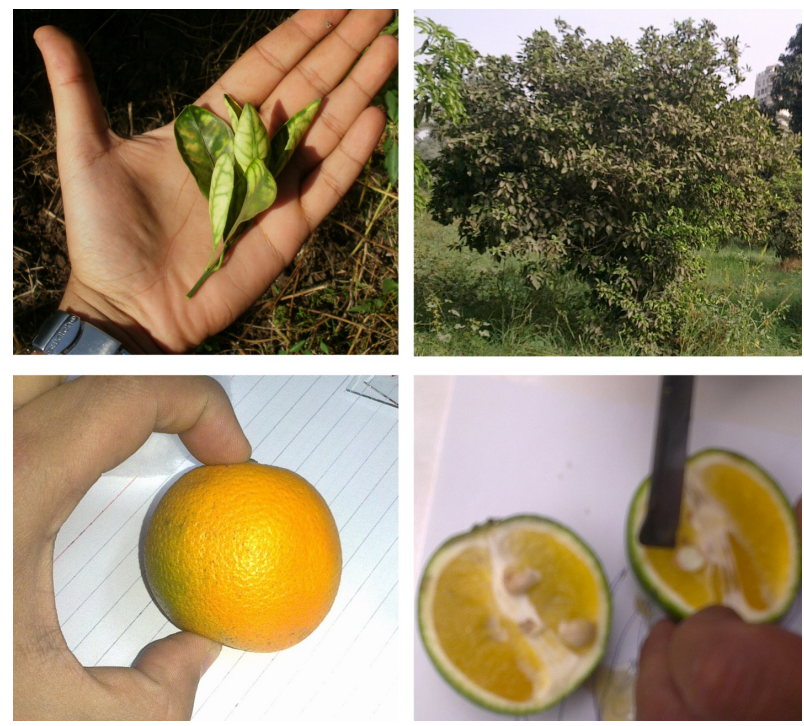

Figure 3. Observed symptoms associated with CSD on the tree, leaves and on fruits of sweet orange.
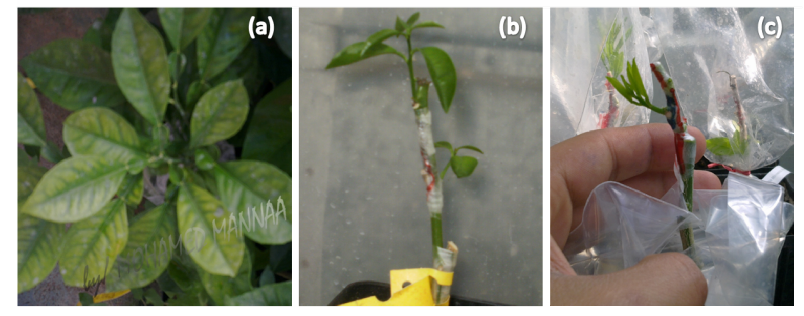

Figure 4. Chlorosis and small cupped leaves symptoms observed on the indicator leaves of $S$. citri infected sample, (a) using traditional method (b) inverse inoculation method (c) inoculated cutting method.

Table 2. Results obtained by comparing the three methods of biological indexing.

\begin{tabular}{cccc}
\hline Method & $\begin{array}{c}\text { Time needed for } \\
\text { observing the } \\
\text { first symptoms }\end{array}$ & $\begin{array}{c}\text { No. of } \\
\text { symptomatic } \\
\text { plants/No. of tested }\end{array}$ & $\begin{array}{c}\text { \% successful } \\
\text { transmission }\end{array}$ \\
\hline $\begin{array}{c}\text { Traditional } \\
\text { method }\end{array}$ & 3 months & $6 / 20$ & $30 \%$ \\
$\begin{array}{c}\text { Inoculated } \\
\text { cutting }\end{array}$ & 5 weeks & $5 / 20$ & $25 \%$ \\
$\begin{array}{c}\text { Inverse } \\
\text { inoculation }\end{array}$ & 4 weeks & $17 / 20$ & $85 \%$ \\
\hline
\end{tabular}

This new improved method, showed to be highly reliable for S. citri indexing on Madame Vinous sweet orange, however some constraints may limit its wide use. As it requires very skilled personnel, good quality and best collection time of the explants used.

Interestingly, this method could be used during the entire year; it can be readily concluded one month after grafting without any transplanting. This method seems to over- come all the constraints of traditional $S$. citri biological indexing, increasing the reliability of symptom expression.

\subsection{Molecular Detection}

Out of the 130 collected suspected symptomatic samples, 96 reacted positively to the PCR assay using the P89 primer pair, and the amplicons of the expected size were produced (Figure 5). On the other hand by using spiralin primer pair, it worked well with samples that were collected in the hottest period of the summer (August), while in the winter; few of the samples produced faint bands of the expected size, such inefficiency of the spiralin primer for $S$. citri detection was explained by Yokomi in 2008.

By using the P58 primer pair, only few samples positively reacted showing the amplicons of the expected size $(450 \mathrm{bp})$, which proof its inefficiency for the detection in comparison with the P89 primer pair. This confirms that the P89 primer pair is efficient and specific for the molecular detection of the Egyptian isolates of S. citri, this is because the P89 primers was designed on sequences obtained from a $S$. citri strain isolated from Morocco (GII3), while the P58 was designed on sequences from $S$. citri strains isolated from America (BR3). This should draw the attention to modify and alternate the routinely used method of detection for CSD in Egypt. The obtained sequence was compared with the other reference strains using BLAST Database, revealing that these Egyptian isolates are genetically close to Moroccan reference strain (GII3), showing 98\% homology of sequences. The sequence was submitted into the Genbank under the accession number HE617172.

\section{Conclusions}

Even if new technologies may improve diagnostic methods, biological indexing is still representing the basis for the detection of most citrus graft-transmissible disease including Stubborn. The use of this technique in combination with laboratory assays, mainly in asymptomatic cuttings, is always recommended for a reliable sanitary

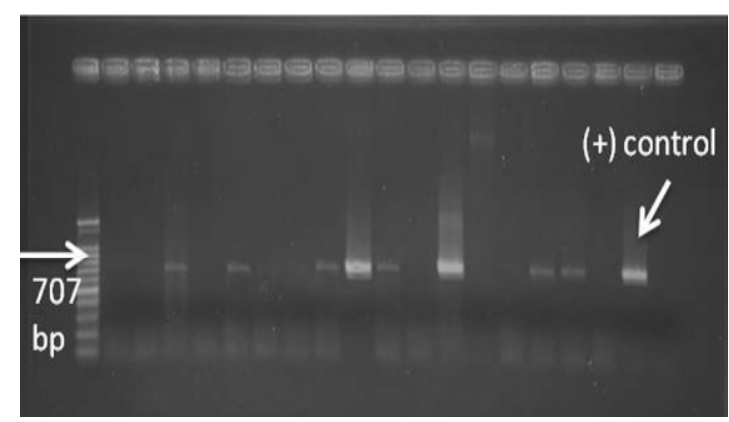

Figure 5. Agarose gel analysis showing PCR amplification (707 bp) of $S$. citri-infected Egyptian samples. 
assessment of a citrus genotype.

The constraints of traditional biological indexing associated with the low $S$. citri concentration, unsatisfactory pathogen transmission in the greenhouse and long time required for symptoms expression, restricted its wide use although it's mandatory to conduct biological indexing in the certification programs. To overcome such limitations, a new more efficient biological indexing technique was set up. This improved inverse inoculation method resulted in a high percentage of successful transmission and a noticeable reduction in the time required for the appearance of typical stubborn symptoms on the indicator leaves.

The PCR assays results prove the efficiency of the P89 primer pair for the molecular detection of the Egyptian isolates of $S$. citri, and so it is recommended to assign this precise method of molecular detection of $S$. citri in Egypt.

These results will help to reveal the true image of the real distribution and spread of CSD, and will also facilitate and improve the citrus certification programs as well as the management of this disease through the early and precise detection even if the pathogen titer is low in the collected samples. This will help for the enhancement of the quality of the produced citrus fruits in Egypt in the future.

\section{REFERENCES}

[1] W. G. Weisburg, J. G. Tully, D. L. Rose, J. P. Petzel, H. Oyaizu, D. Yang, L. Mandelco, J. Sechrest, T. G. Lawrence, J. Van Etten, J. Maniloff and C. R. Woese, "A Phylogenetic Analysis of the Mycoplasmas: Basis for Their Classification," Journal of Bacteriology, Vol. 171, No. 12, 1989, pp. 6455-6467.

[2] F. Nour El-Din, “A Tumor-Enduing Agent Associated with Citrus Trees Infected with Safargali (Stubborn) Disease in UM," Phytopath, Vol. 57, 1967, pp. 108-113.

[3] A. A. Abu-Zeid, A. A. Kishtah and E. M. Khalil, "Isolation and Culturing of Spiroplasma citri Associated with Stubborn Disease of Citrus in Egypt," Journal of Phytopathology, Vol. 20, No. 2, 1988, pp. 139-140.

[4] fas.usda.gov [Internet], "Citrus: World Markets and Trade, United States Department of Agriculture," Foreign Agricultural Services, 2011.

http://www.fas.usda.gov/htp/2011_Jan_Citrus.pdf

[5] E. Sheta, E. S. Salem, A. M. Abou-Zeid, M. Osman, M. A. Shafik and A. El-Hawari, "Development of a Citrus Certification Program in Egypt," Proceedings of the 15th Conference of the International Organization of Citrus Virologists (IOCV), Riverside, 3-6 November 2004, pp. 321-329.

[6] I. M. Lee and R. E. Davis, "New Media for Rapid Growth of Spiroplasma citri and Corn Stunt Spiroplasma," Phytopath, Vol. 74, 1983, pp. 84-89. doi:10.1094/Phyto-74-84

[7] C. N. Roistacher, "Graft-Transmissible Diseases of Citrus. Handbook for Detection and Diagnosis," FAO, Rome, 1991, p. 286.

[8] J. J. Doyle, "DNA Protocols for Plants," In: A. B. Hewitt, B. Johnson and J. P. W. Young, Eds., Molecular Techniques in Taxonomy, NATO Scientific Affairs Division, England, 1991.

[9] X. Foissac, C. Saillard, J. Gandar, L. Zreik and M. J. Bové, "Spiralin Polymorphism in Strains of Spiroplasma citri Is Not Due to Differences in Posttranslational Palmitoylation," Journal of Bacteriology, Vol. 178, 1996, pp. 2934 2940.

[10] R. K. Yokomi, A. F. S. Mello, M. Saponari and J. Fletcher, "Polymerase Chain Reaction Based Detection of Spiroplasma citri Associated with Citrus Stubborn Disease," Plant Disease, Vol. 92, No. 2, 2008, pp. 253-260. doi:10.1094/PDIS-92-2-0253 